\title{
LUM Imaging System
}

National Cancer Institute

\section{Source}

National Cancer Institute. LUM Imaging System. NCI Thesaurus. Code C157052.

A proprietary imaging system designed to detect residual tumor tissue in breast cancer patients by identifying microscopic residual cancer in the tumor bed. The LUM Imaging System consists of the cancer imaging agent LUM015 and a hand-held fluorescencebased imager that detects the emission of activated LUM015 in and around a tumor. The LUM Imaging System is designed to detect microscopic residual cancer cells in real-time. 